Research Article

\title{
A Nonlinear Dynamic Foundation Model for Dynamic Response of Track-Train Interaction
}

\author{
Phuoc T. Nguyen (iD, ${ }^{1}$ Trung D. Pham, ${ }^{2}$ and Hoa P. Hoang ${ }^{3}$ \\ ${ }^{1}$ Department of Civil Engineering, Ho Chi Minh City Open University, 97 Vo Van Tan Street, Ho Chi Minh City, Vietnam \\ ${ }^{2}$ Department of Civil Engineering, Mientrung University of Civil Engineering, 24 Nguyen Du Street, Tuy Hoa City, Vietnam \\ ${ }^{3}$ Department of Construction of Bridge and Road, University of Science and Technology, The University of Danang, \\ 54 Nguyen Luong Bang St., Danang City, Vietnam \\ Correspondence should be addressed to Phuoc T. Nguyen; phuoc.nguyen@ou.edu.vn
}

Received 2 June 2019; Revised 31 August 2019; Accepted 4 October 2019; Published 4 March 2020

Academic Editor: Evgeny Petrov

Copyright (C) 2020 Phuoc T. Nguyen et al. This is an open access article distributed under the Creative Commons Attribution License, which permits unrestricted use, distribution, and reproduction in any medium, provided the original work is properly cited.

\begin{abstract}
The paper studies the dynamic response of track-train interaction on a nonlinear dynamic foundation model with special things such as (i) the nonlinear dynamic foundation model includes a nonlinear elastic spring, shear layer, viscous damping, and foundation mass; (ii) the process of the finite-element method of nonlinear dynamic response of the foundation and track-train interaction is established clearly; (iii) the numerical results show that the foundation mass has a significant effect on the dynamic characteristic of the structure system and dynamic response of track-train interaction under a moving vehicle and almost have more increasing dynamic displacements than others without the effect of the foundation mass. Therefore, it can be seen that the study has meaning practice, and the foundation quite agrees to describe the true behaviour of soil in the problems of the dynamic response of structures on the foundation.
\end{abstract}

\section{Introduction}

The problem model of structures on the foundation subjected to moving load has a very important meaning in the practical application such as road-vehicle and track-train interaction. Hence, the problem was attracted by many researchers in many decades. In almost all the studies, the foundation model applied to analyze the dynamic response of structures was described by various foundation models. The first is the one-parameter foundation model. Winkler [1] described it by the linear or nonlinear elastic spring [2-11]. However, the most important deficiency of the above foundation model is that it does not have displacement continuity on the foundation surface and it does not have any discontinuity between the loaded and the unloaded part in reality. So, it was developed into the many-parameter foundation models to overcome the above deficiencies as done by Filonenko-Borodich [12], Hetényi [13], Pasternak [14], Reissner [15], and Kerr [16], and these models have been also applied in many problems for analyzing a response of the structure-foundation interactions [17-33].

However, the common character of the above foundation models is that they used the elastic spring without density to describe the behaviour of the foundation [1-33]. Then, the nature of the foundation has density, and it does not have influence on the problem of static analysis, but it can have an influence on the problem of dynamic analysis. When the aforementioned structure is vibrating under dynamic load, the foundation mass also causes vertical inertia force as the external load on the structures. The force depends on the value of mass and motion acceleration of the foundation, and it completely participates in the response to the above structures [34]. Hence, a new foundation model based on the above foundation models, called "dynamic foundation model," is proposed to describe the nearly true behaviour of soil [34-37]. It can be seen that the dynamic foundation model quite agrees with developing tendency, and it has inheritability from the last foundation models. 
So, the foundation mass has to produce an effect on the dynamic response of track-train interaction, and it does not also have any research which presents the effects of the foundation mass on the dynamic response of track-train interaction. Hence, the purpose of this study investigates the influence of the foundation mass on the dynamic response of track-train interaction. In this study, the nonlinear dynamic foundation is described by a linear and nonlinear elastic spring, the shear layer, and the viscous damping and the special effects of parameters of foundation mass density during vibration and the processes of the finite-element method of the nonlinear response of the foundation and track-train interaction are established clearly. It can be seen that the study has meaning practice and the foundation model quite agrees to describe the true behaviour of soil in dynamic analysis response of track-train interaction.

\section{Formulation}

2.1. Problem Model of Track-Train Interaction. A track-train model [38] on the nonlinear dynamic foundation is plotted in Figure 1.

2.2. Nonlinear Dynamic Foundation Model. The foundation model is described by an elastic spring including linear and nonlinear elastic springs, $k$ and $k_{\mathrm{NL}}$, respectively, shear layer $k_{\mathrm{s}}$, viscous damping $c$, and foundation mass density $\rho_{\mathrm{F}}$, respectively, replaced by lumped mass $m$ connected between the elastic layer and the shear layer, shown in Figure 2.

At the time $t$, the relationship between pressure and deflection under a pressure $q(x, y, t)$ is established based on the principle of dynamic balance and is given by

$$
\begin{aligned}
q(x, y, t)= & k_{\mathrm{eff}} w(x, y, t)+c \frac{\partial w(x, y, t)}{\partial t} \\
& +m \frac{\partial^{2} w(x, y, t)}{\partial t^{2}}-k_{\mathrm{S}} \nabla^{2} w(x, y, t),
\end{aligned}
$$

where $k_{\text {eff }}$ is effectiveness stiffness depending on the time deflection at each point of the foundation and $m$ is the lumped mass and can be expressed as [35]

$$
\begin{aligned}
k_{\text {eff }} & =k_{\mathrm{w}}+k_{\mathrm{NL}} w^{2}(x, y, t), \\
m & =\beta \rho_{\mathrm{F}},
\end{aligned}
$$

in which $\beta$ is a characteristic parameter of the influence of the foundation mass.

2.3. Formulation of Element Matrices. The track on the nonlinear dynamic foundation is modelled as an Euler-Bernoulli beam having two nodes and each node has two degrees of freedom including vertical and rotation displacements, plotted in Figure 3.

Based on the strain energy of the beam element on the foundation including the effects of both the beam and foundation, the stiffness matrix of the element is plotted as

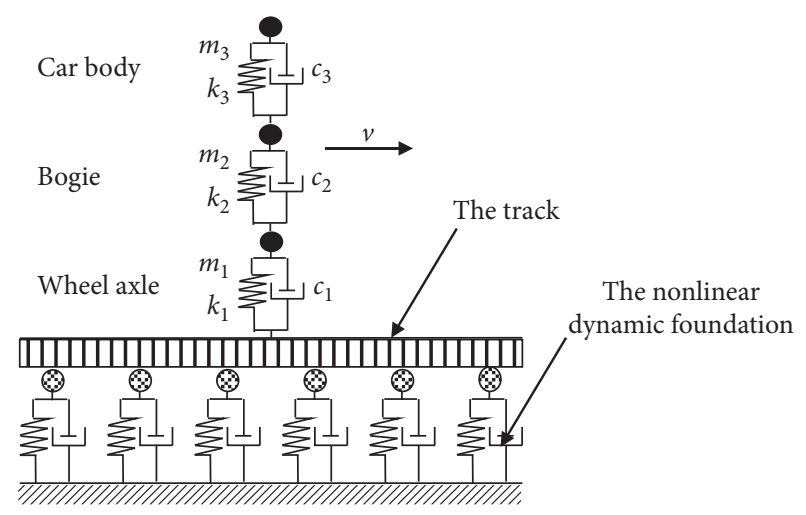

FIGURE 1: The problem model of track-train interaction.

$$
[\mathbf{K}]_{\mathrm{e}}=[\mathbf{K}]_{\mathrm{b}}+[\mathbf{K}]_{\mathrm{w}}+[\mathbf{K}]_{\mathrm{s}},
$$

where $[\mathbf{K}]_{\mathrm{b}}$ is the stiffness matrix of the beam, $[\mathbf{K}]_{\mathrm{w}}$ is the stiffness matrix of elastic foundation, and $[\mathbf{K}]_{s}$ is the stiffness matrix of the shear layer, respectively, and are given by

$$
\begin{aligned}
{[\mathbf{K}]_{\mathrm{W}} } & =\int_{0}^{l}\left[\mathbf{N}_{\mathrm{w}}\right]^{T} k_{\mathrm{eff}}\left[\mathbf{N}_{\mathrm{w}}\right] \mathrm{d} x, \\
{[\mathbf{K}]_{\mathrm{s}} } & =\int_{0}^{l}\left[\mathbf{N}_{\mathrm{s}}\right]^{T} k_{\mathrm{s}}\left[\mathbf{N}_{\mathrm{s}}\right] \mathrm{d} x .
\end{aligned}
$$

The mass matrix of the element including the effects of both the beam and the foundation is determined based on the kinetic energy of the beam element on the foundation and is given as

$$
[\mathbf{M}]_{\mathrm{e}}=[\mathbf{M}]_{\mathrm{b}}+[\mathbf{M}]_{\mathrm{F}},
$$

where $[\mathbf{M}]_{\mathrm{b}}$ is the mass matrix of the beam and $[M]_{\mathrm{F}}$ is the mass matrix for foundation mass inertia, respectively, and can be expressed as

$$
[\mathbf{M}]_{\mathrm{F}}=\int_{0}^{l}\left[\mathbf{N}_{\mathrm{w}}\right]^{T} m\left[\mathbf{N}_{\mathrm{w}}\right] \mathrm{d} x .
$$

The viscous damping property of the foundation is considered to be the dashpots system. Based on the dissipation energy of these dashpots, the damping matrix of the element is given by

$$
[\mathbf{C}]_{\mathrm{e}}=\int_{0}^{l}\left[\mathbf{N}_{\mathrm{w}}\right]^{T} c\left[\mathbf{N}_{\mathrm{w}}\right] \mathrm{d} x,
$$

where $\left[\mathbf{N}_{\mathrm{w}}\right]$ and $\left[\mathbf{N}_{\mathrm{s}}\right]$ are the shaping function matrices for displacements and rotation presented in many types of research related to the finite-element method, respectively.

2.4. Governing Equation of Motion. However, other types of vibrations like track-train vibration mainly caused by corrugation of the track and horizontal vibrations due to changes in track direction which affect the performance of the track-train interaction are not studied in this study. This is because the main purpose of this study is to investigate the influence of the foundation model on the track-train interaction. At the same time, by assuming no loss of contact force between the train and the upper smooth surface of the 


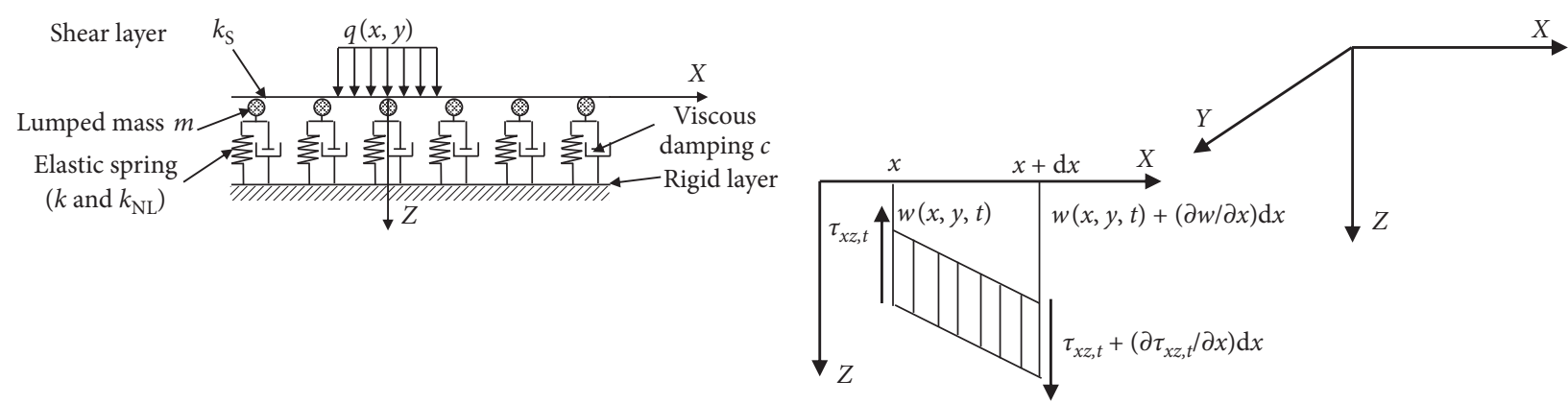

(a)

(b)

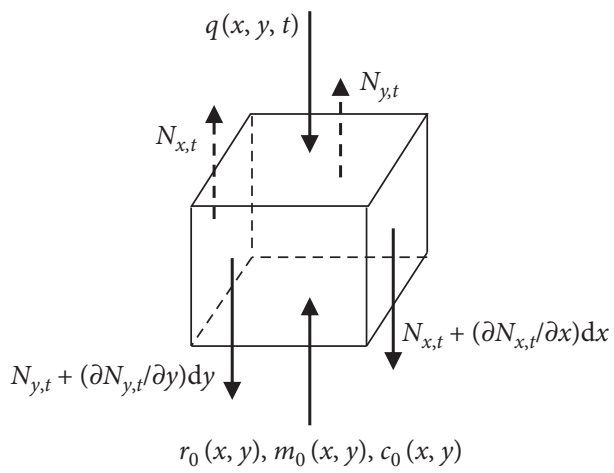

(c)

Figure 2: The nonlinear dynamic foundation model: (a) basic foundation model, (b) stress in the shear layer, and (c) acting forces on the shear layer.

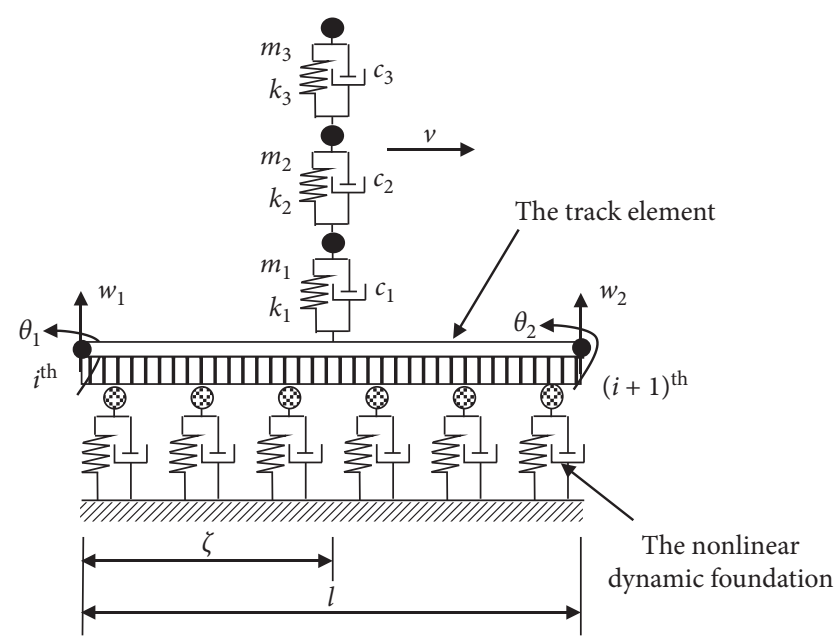

Figure 3: The track-train interaction element.

track, the governing equations of the vehicle model at time $t$ are given by

$$
\begin{gathered}
m_{1} \ddot{u}_{1}+c_{2}\left(\dot{u}_{1}-\dot{u}_{2}\right)+k_{2}\left(u_{1}-u_{2}\right)=m_{1} g-F(t), \\
m_{2} \ddot{u}_{2}+c_{2}\left(\dot{u}_{2}-\dot{u}_{1}\right)+k_{2}\left(u_{2}-u_{1}\right) \\
\quad+c_{3}\left(\dot{u}_{2}-\dot{u}_{3}\right)+k_{3}\left(u_{2}-u_{3}\right)=m_{2} g, \\
m_{3} \ddot{u}_{3}+c_{3}\left(\dot{u}_{3}-\dot{u}_{2}\right)+k_{3}\left(u_{3}-u_{2}\right)=m_{3} g,
\end{gathered}
$$

$$
F(t)=c_{1}\left(\dot{u}_{1}-\dot{z}_{c}\right)+k_{1}\left(u_{1}-z_{c}\right)
$$

where $z_{c}$ and $\dot{z}_{c}$ denote the displacement and velocity at the contact point between the wheel and rail at time $t$, respectively. They are determined based on the displacement and velocity vector of the rail element, given by

$$
\begin{aligned}
& z_{\mathrm{c}}=\left[\mathbf{N}_{\mathrm{w}, \xi}\right]\{\mathbf{u}\}_{\mathrm{e}}, \\
& \dot{z}_{\mathrm{c}}=\left[\mathbf{N}_{\mathrm{w}, \xi}\right]\{\dot{\mathbf{u}}\}_{\mathrm{e}} .
\end{aligned}
$$

Substituting equation (13) into (9), the contact force between the wheel and rail at time $t$ is also plotted:

$$
F(t)=c_{1} \dot{u}_{1}+k_{1} u_{1}-\left(c_{1}\left[\mathbf{N}_{\mathrm{w}, \xi}\right]\{\dot{\mathbf{u}}\}_{\mathrm{e}}+k_{1}\left[\mathbf{N}_{\mathrm{w}, \xi}\right]\{\mathbf{u}\}_{\mathrm{e}}\right) .
$$

Then, substituting equation (15) into (10), the governing equations for the vehicle model at time $t$ can be expressed in terms of the matrix as

$$
\begin{gathered}
{\left[\begin{array}{ccc}
m_{1} & 0 & 0 \\
0 & m_{2} & 0 \\
0 & 0 & m_{3}
\end{array}\right]\left\{\begin{array}{l}
\ddot{u}_{1} \\
\ddot{u}_{2} \\
\ddot{u}_{3}
\end{array}\right\}+\left[\begin{array}{ccc}
c_{2} & -c_{2} & 0 \\
-c_{2} & c_{2}+c_{3} & -c_{3} \\
0 & -c_{3} & c_{3}
\end{array}\right]\left\{\begin{array}{l}
\dot{u}_{1} \\
\dot{u}_{2} \\
\dot{u}_{3}
\end{array}\right\}} \\
+\left[\begin{array}{ccc}
k_{2} & -k_{2} & 0 \\
-k_{2} & k_{2}+k_{3} & -k_{3} \\
0 & -k_{3} & k_{3}
\end{array}\right]\left\{\begin{array}{l}
u_{1} \\
u_{2} \\
u_{3}
\end{array}\right\}=\left\{\begin{array}{c}
m_{1} g-F(t) \\
m_{2} g \\
m_{3} g
\end{array}\right\} .
\end{gathered}
$$


For the track, the equation of motion for the track element $i^{\text {th }}$ without the effect of material damping is given by

$$
[\mathbf{M}]_{\mathrm{e}}\left\{\ddot{\mathbf{u}}_{\mathrm{e}}\right\}+[\mathbf{C}]_{\mathrm{e}}\left\{\dot{\mathbf{u}}_{\mathrm{e}}\right\}+[\mathbf{K}]_{\mathrm{e}}\left\{\mathbf{u}_{\mathrm{e}}\right\}=-\left[\mathbf{N}_{\mathrm{w}, \xi}\right]^{T} F(t) \delta\left(\xi-v t+i^{\text {th }} l\right),
$$

where $\left\{\mathbf{u}_{\mathrm{e}}\right\}$ is the displacement vector of the track element, $\left[\mathbf{N}_{\mathrm{w}, \xi}\right]$ is the value of shape function in local coordinate $\xi$, and $\delta\left(\xi-v t+i^{\text {th }} l\right)$ is the Dirac-delta function.

By assembling the corresponding matrices of the combined track-train model in the global coordinate, the system equation of motion of the track-train interaction model is written by

$$
[\mathbf{M}]\{\ddot{\mathbf{z}}\}+[\mathbf{C}]\{\dot{\mathbf{z}}\}+[\mathbf{K}]\{\mathbf{z}\}=\{\mathbf{P}(t)\},
$$

in which $[\mathbf{M}],[\mathbf{C}]$, and $[\mathbf{K}]$ are the overall matrix of mass, damping, and stiffness, respectively; $\{\mathbf{z}\}$ is the overall vector of displacement; while $\{\mathbf{P}(t)\}$ is the overall force vector of the combined track-train model, respectively. The symbol $[\mathbf{K}]$ is called instantaneous matrices because it depends on time deflection at each point of the foundation.

Equation (17) is used to analyze the dynamic response of the track-train interaction based on Newmark's algorithm. The computer program for analyzing this above problem is developed based on the Matlab language with a flowchart for the numerical procedure as in Figure 4.

\section{Numerical Study}

3.1. Verified Example. To verify the reliability of the computer program developed by the authors based on the above formulation, the results are compared with available results in the literature. The time history of displacement of the middle of the beam is investigated and compared with the results of [10], as shown in Figure 5.

It can be that the results of the present method are in quite agreement with the results in the literature. The examples will demonstrate the excellent performance of the proposed algorithm to illustrate the track-train interaction. Therefore, the program which analyzed the effect of the parameters of nonlinear dynamic foundation on the dynamic response of the track-train interaction is reliable.

3.2. Numerical Investigation. To analyze the effects of the foundation mass on the dynamic response of track-train interaction, the material properties of the track, foundation, and moving vehicle model are presented in Table 1 .

In the first investigation, the influence of foundation properties on the dynamic response of the track is investigated in both linear and nonlinear dynamic foundations. Figure 6 plots the influence of the foundation model without the effect of the foundation mass on the history of vertical displacement of the track. It can be seen that the nonlinear dynamic foundation has more increasing dynamic response of the track than the linear dynamic foundation because the behaviour of linear dynamic foundation is not as similar to the true behaviour of soil as the nonlinear dynamic foundation, as shown in Figure 6.

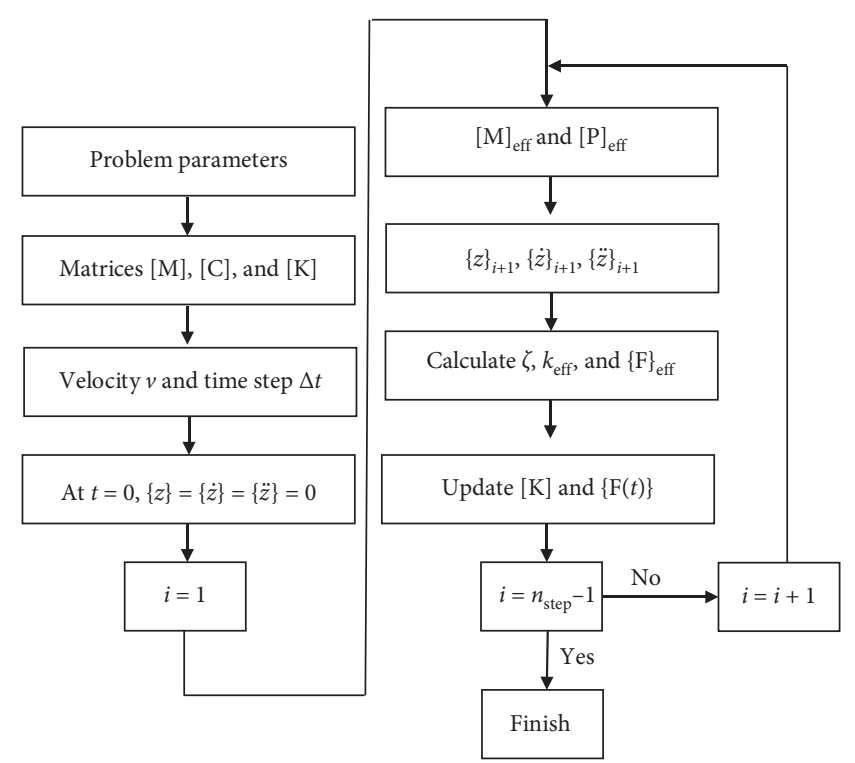

FIGURE 4: Flowchart for the numerical procedure.

Besides, the effect of foundation properties such as viscous damping and linear and nonlinear stiffness on the dynamic response of track is also studied, shown in Figures 7 and 8 , respectively.

It can be seen that the foundation properties affect the dynamic characteristics of the system and decrease the history of vertical displacements of the track with an increase of the foundation properties. An increase in the value of linear and nonlinear stiffness of the foundation causes an increase in the elastic stiffness of the dynamic foundation as well as it causes an increase in the global stiffness of the structural beam system. Therefore, it decreases the time history of the dynamic response of track-train interaction, as shown in Figures 7 and 8.

In the next numerical investigation, the effect of the foundation mass in the linear dynamic foundation on the dynamic response of track-train interaction is investigated. Figure 9 presents the history of vertical displacements of the middle of the track for various values of the moving velocity of the vehicle. It can be seen that the dynamic characteristic of the structure system was changed by the foundation mass. The properties of track-train interaction are constant, and the stiffness of foundation is also not variable. Consequently, the foundation mass caused the added mass during vibration. Therefore, it causes an increase in the general vibration mass of the structure system as mean as the structural system will become softer, and then it will also more increasing the dynamic response than without effect of the foundation mass, as shown in Figure 9.

According to the above analysis, the influence of the foundation mass on the history of vertical displacement of the track is not similar. It is clearly different from various values of velocities of the moving train. With a range of high velocities, the influence of the foundation mass on the dynamic response of the track is clearer than the range of low velocities. Hence, the influence of the foundation mass on the dynamic response of the track with a various range of 


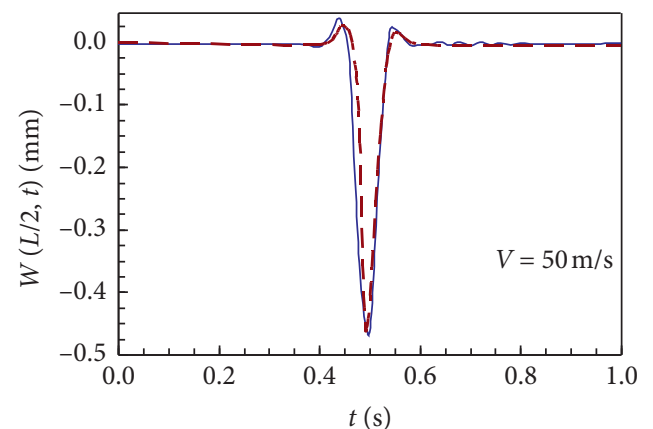

- Present

-- - Reference [10]

(a)

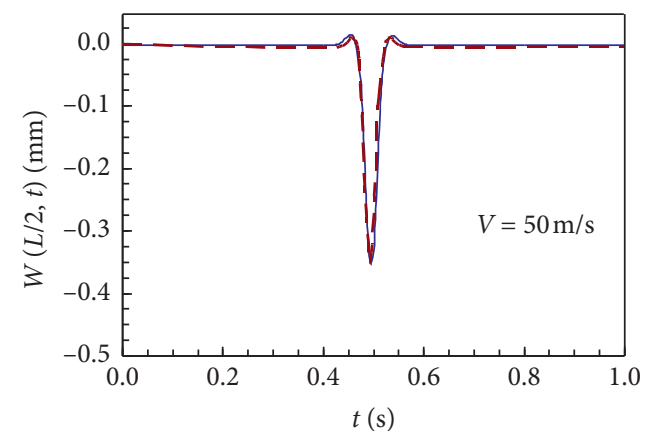

- Present

- - - Reference [10]

(b)

FIGURE 5: The time history of dynamic response of the beam: (a) nonlinear foundation and (b) linear foundation.

TAble 1: Properties of track, vehicle, and dynamic foundation.

\begin{tabular}{|c|c|c|c|}
\hline \multicolumn{4}{|l|}{ Track [5] } \\
\hline Young's modulus & $E$ & $\mathrm{~N} / \mathrm{m}^{2}$ & $2.1 \times 10^{11}$ \\
\hline Mass density & $\rho$ & $\mathrm{kg} / \mathrm{m}^{3}$ & 7850 \\
\hline Cross-sectional area & $A$ & $\mathrm{~m}^{2}$ & $7.69 \times 10^{-3}$ \\
\hline Second moment of area & $I$ & $\mathrm{~m}^{4}$ & $3.055 \times 10^{-5}$ \\
\hline \multicolumn{4}{|l|}{ Nonlinear dynamic foundation [5] } \\
\hline Equivalent stiffness & $k_{\mathrm{L}}$ & $\mathrm{N} / \mathrm{m}^{2}$ & $138.60 \times 10^{6}$ \\
\hline Linear stiffness & $k$ & $\mathrm{~N} / \mathrm{m}^{2}$ & $35.03 \times 10^{6}$ \\
\hline Nonlinear stiffness & $k_{\mathrm{NL}}$ & $\mathrm{N} / \mathrm{m}^{4}$ & $4.01 \times 10^{14}$ \\
\hline Shear parameter & $k_{\mathrm{s}}$ & $\mathrm{N}$ & 66687500 \\
\hline Viscous damping & $c$ & $\mathrm{Ns} / \mathrm{m}^{2}$ & $1732.5 \times 10^{3}$ \\
\hline Foundation mass density & $\rho_{\mathrm{f}}$ & $\mathrm{kg} / \mathrm{m}^{3}$ & 1900 \\
\hline \multicolumn{4}{|l|}{ Vehicle [38] } \\
\hline Wheel axle & $m_{1}$ & $\mathrm{~kg}$ & 350 \\
\hline Bogie & $m_{2}$ & $\mathrm{~kg}$ & 250 \\
\hline Car body & $m_{3}$ & $\mathrm{~kg}$ & 3500 \\
\hline Spring of contacting suspension & $k_{1}$ & $\mathrm{~N} / \mathrm{m}$ & $8 \times 10^{9}$ \\
\hline Spring of primary suspension & $k_{2}$ & $\mathrm{~N} / \mathrm{m}$ & $1.26 \times 10^{6}$ \\
\hline Spring of second suspension & $k_{3}$ & $\mathrm{~N} / \mathrm{m}$ & $1.41 \times 10^{5}$ \\
\hline Dashpot of contacting suspension & $c_{1}$ & $\mathrm{Ns} / \mathrm{m}$ & $6.70 \times 10^{5}$ \\
\hline Dashpot of primary suspension & $c_{2}$ & $\mathrm{Ns} / \mathrm{m}$ & $7.10 \times 10^{3}$ \\
\hline Dashpot of second suspension & $c_{3}$ & $\mathrm{Ns} / \mathrm{m}$ & $8.87 \times 10^{3}$ \\
\hline
\end{tabular}

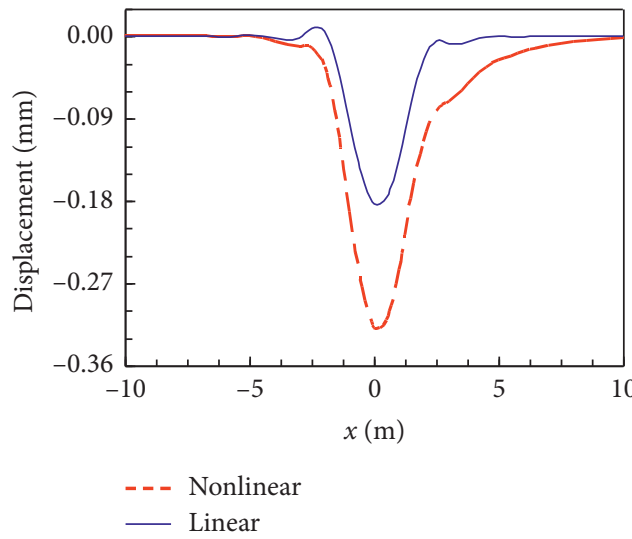

(a)

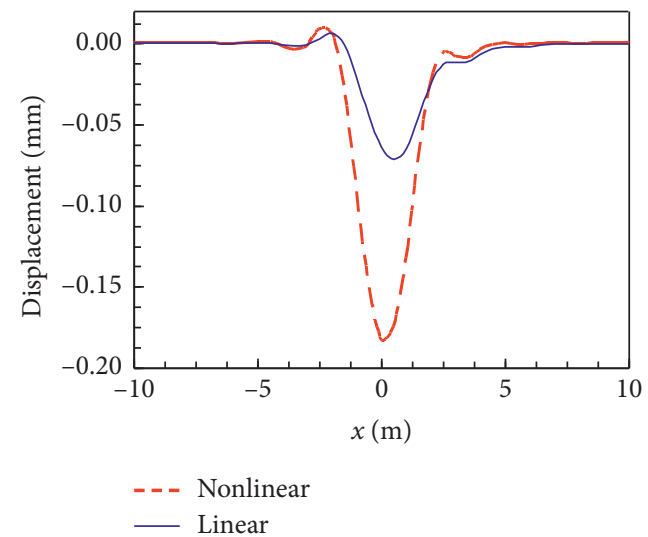

(b)

Figure 6: The history of vertical displacement at the middle of the track corresponding with location of the moving vehicle in both the foundation model: (a) $v=25 \mathrm{~m} / \mathrm{s}$ and (b) $v=75 \mathrm{~m} / \mathrm{s}$. 


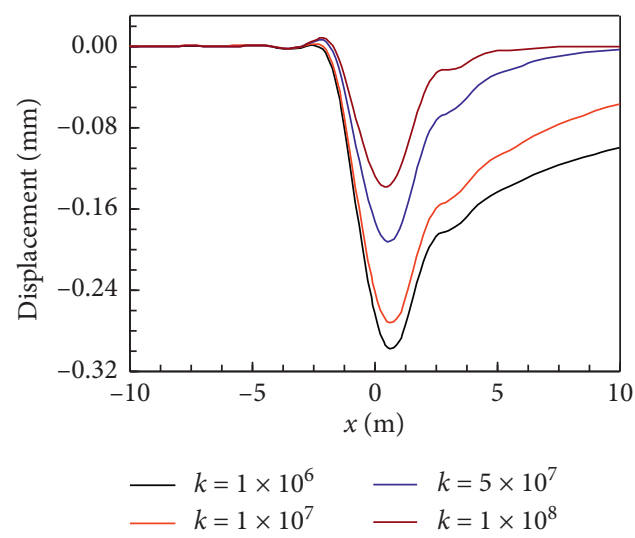

(a)

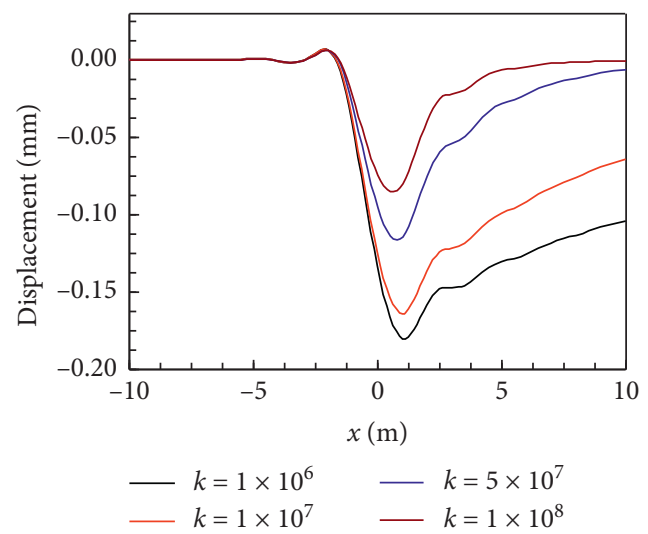

(b)

Figure 7: The effect of linear stiffness on the history of vertical displacement at the middle of the track corresponding with location of the moving vehicle: (a) $v=50 \mathrm{~m} / \mathrm{s}$ and (b) $v=75 \mathrm{~m} / \mathrm{s}$.

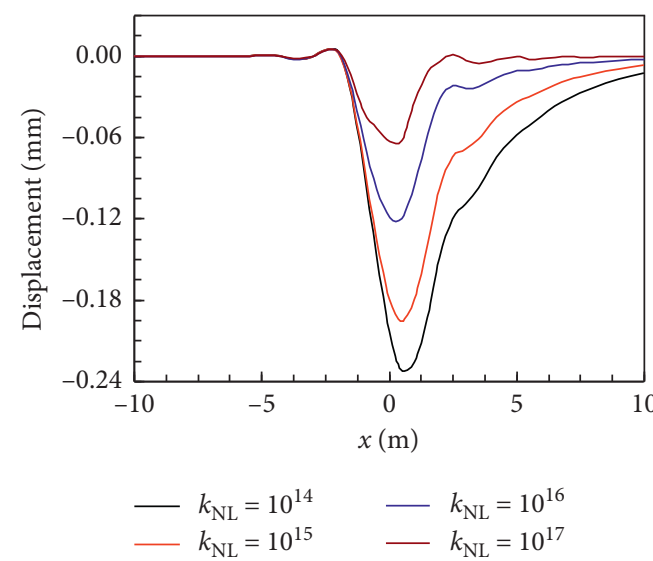

(a)

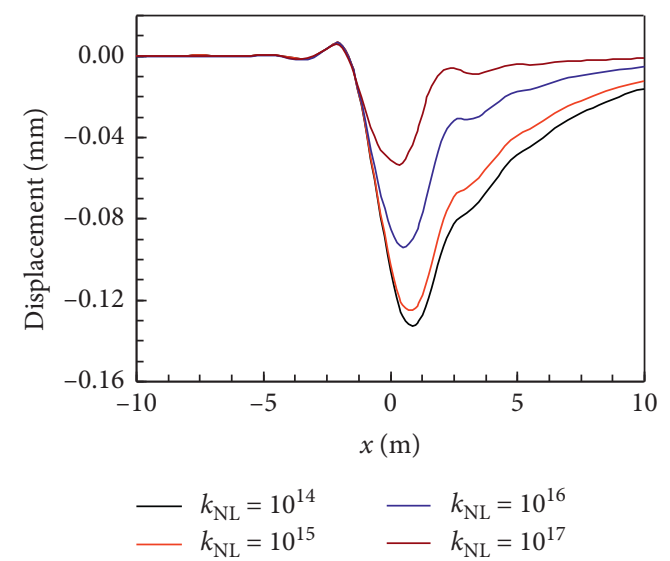

(b)

FIGURE 8: The effect of nonlinear stiffness on the history of vertical displacement at the middle of the track corresponding with location of the moving vehicle: (a) $v=50$ and (b) $v=75 \mathrm{~m} / \mathrm{s}$.

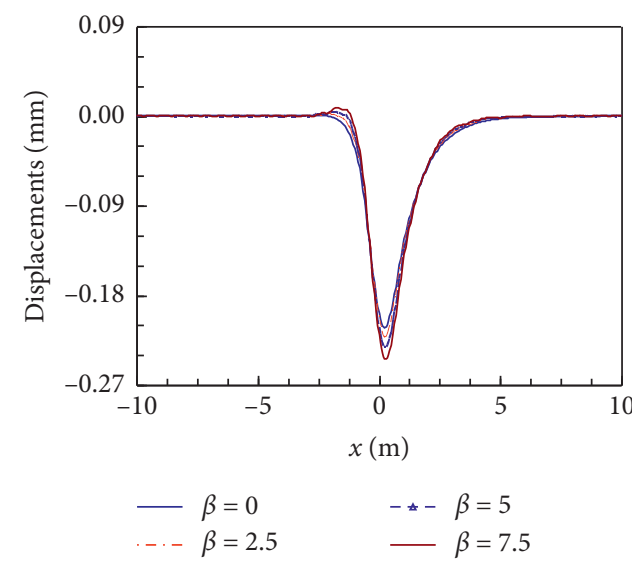

(a)

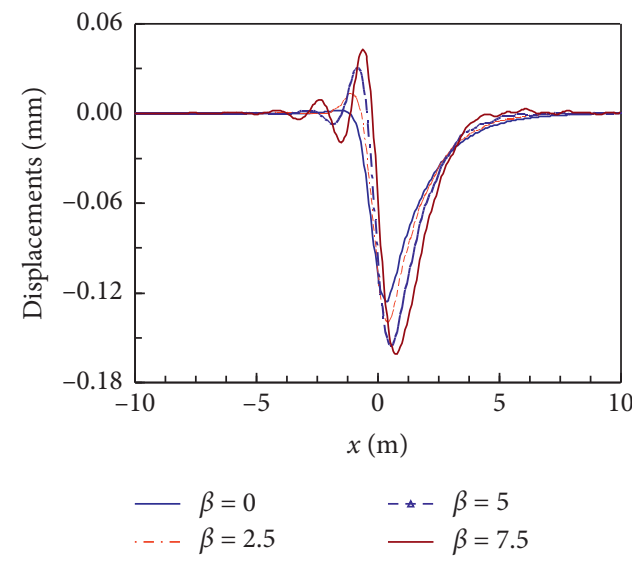

(b)

FIGURE 9: The history of vertical displacements at the middle of the track corresponding with location of the moving vehicle: (a) $v=50 \mathrm{~m} / \mathrm{s}$ and (b) $v=100 \mathrm{~m} / \mathrm{s}$. 


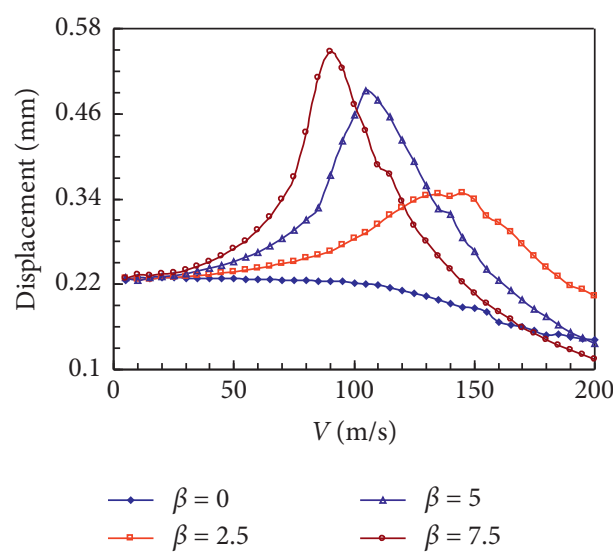

(a)

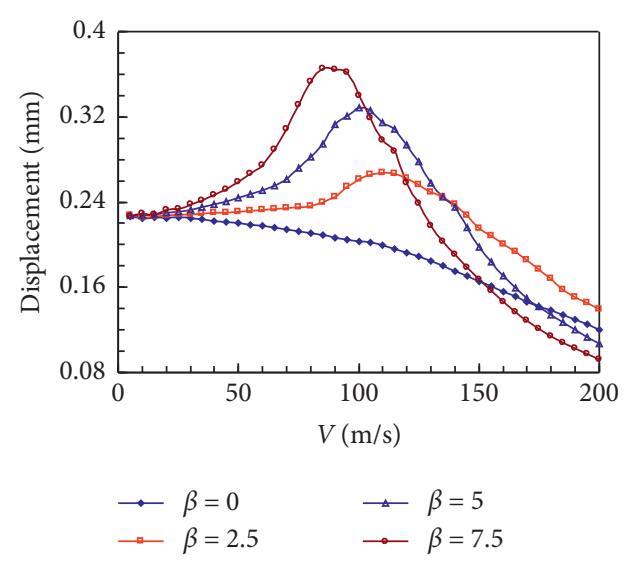

(b)

FIgURE 10: The maximum displacements of the track with various viscous damping: (a) $c=5 \times 10^{5} \mathrm{Ns} / \mathrm{m}^{2}$ and (b) $c=1 \times 10^{6} \mathrm{Ns} / \mathrm{m}^{2}$.

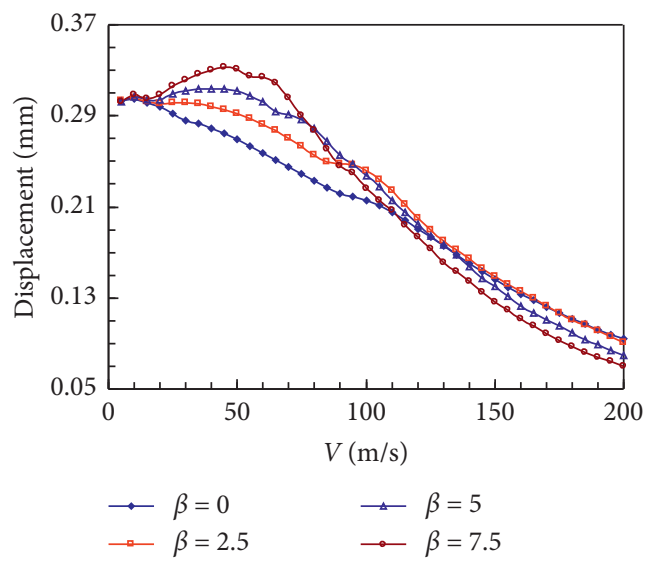

(a)

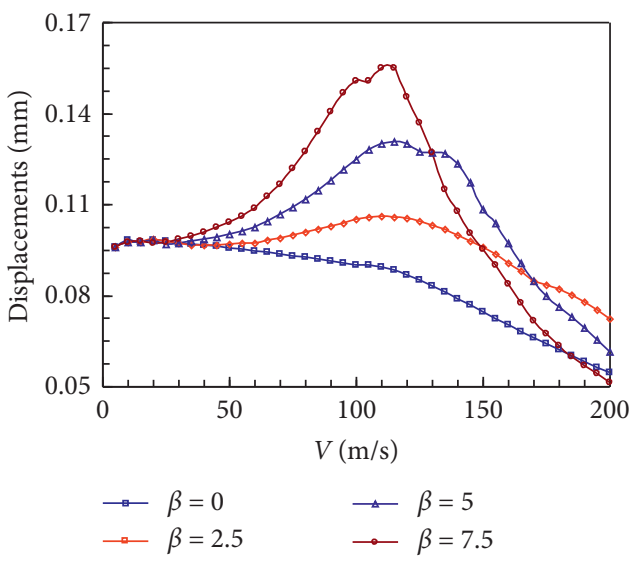

(b)

FIGURE 11: The maximum displacements of the track with various elastic stiffness: (a) $k=138.6 \times 10^{6} \mathrm{~N} / \mathrm{m}^{2}$ and (b) $k=500 \times 10^{6} \mathrm{~N} / \mathrm{m}^{2}$.

moving velocities is investigated. The maximum vertical displacements of the middle of the track with various values of viscous damping, elastic, and shear stiffness for various values of the moving velocities of the train are plotted in Figures 10-12.

It can be seen that the foundation mass has a significant effect on the dynamic characteristics of the structure system, and it increases the vertical displacement of the track comparatively higher than without the foundation mass. At the same time, in the range of low velocities, the effect of the foundation mass is not true, and in the range of high velocities, the effects are clearly shown. It can be seen that the influence of the foundation mass on the dynamic response to the track-train interaction is different, the addition of the global mass of the structural system caused by the foundation mass during the time vibration changed the dynamic character of the structure, and then it changes the domain of frequency resonance of the structural system due to the dynamic load as a moving vehicle. Hence, the influence of the foundation mass on the time history of the track-train interaction is different with a variable value of the moving velocities. Nevertheless, the foundation mass causes an increase in the time history of the dynamic response to the track-train interaction in almost all the cases, as shown in Figures 10-12.

Continuously, the influence of the foundation mass on the dynamic response of the train is also considered in many cases of velocity and a characteristic parameter of the foundation mass. Figure 13 presents the influence of the foundation mass on the history of vertical displacement of the wheel axle. It can be seen that the foundation mass changed the dynamic characteristic of the system, and then it also changed the contacting character between the vehicle and the track. Hence, the history of vertical displacement of the wheel axle is more when compared without the foundation mass. It can be as well seen that the influence has meaning in problem analyzing and 


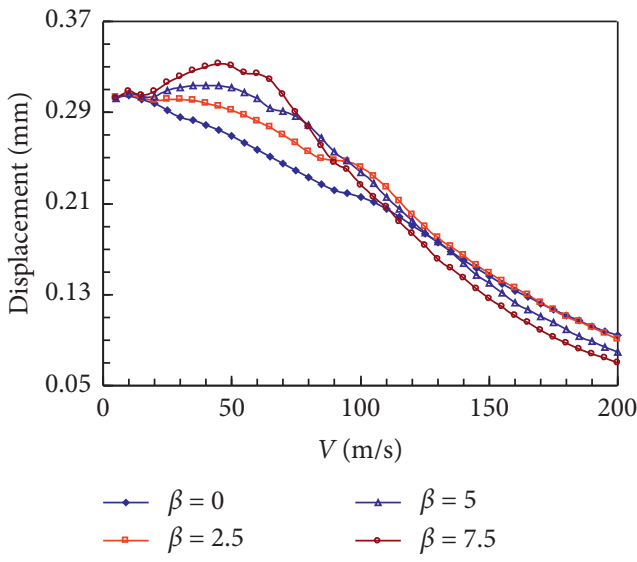

(a)

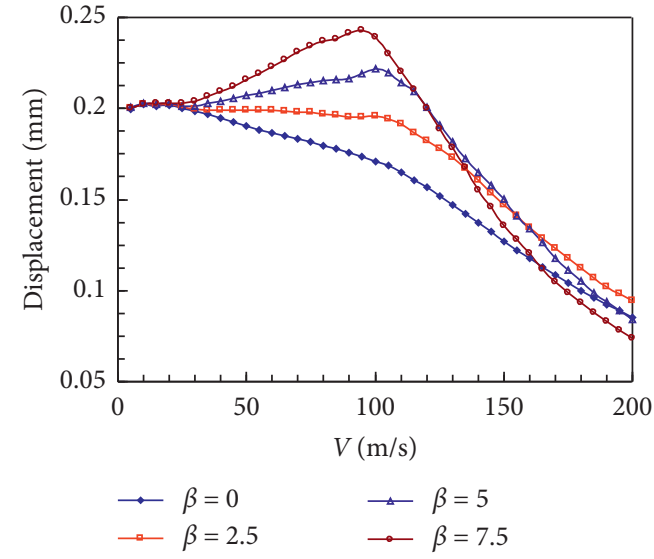

(b)

FIgURE 12: The maximum displacements of the track with various shear stiffness: (a) $k_{\mathrm{s}}=1 \times 10^{7} \mathrm{~N}$ and (b) $k_{\mathrm{s}}=1 \times 10^{8} \mathrm{~N}$.

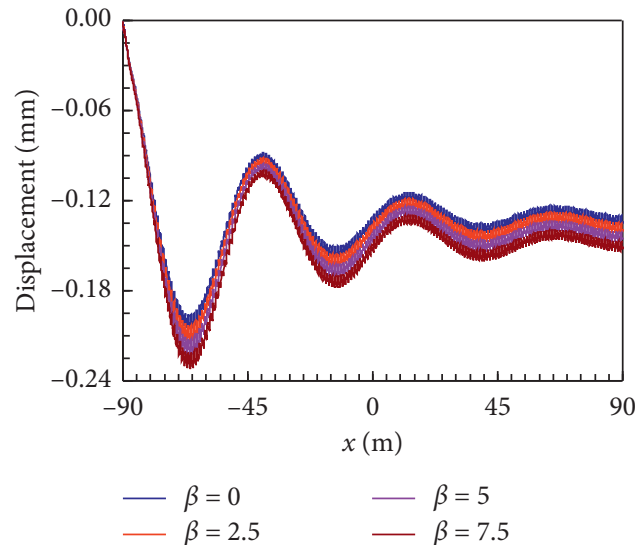

(a)

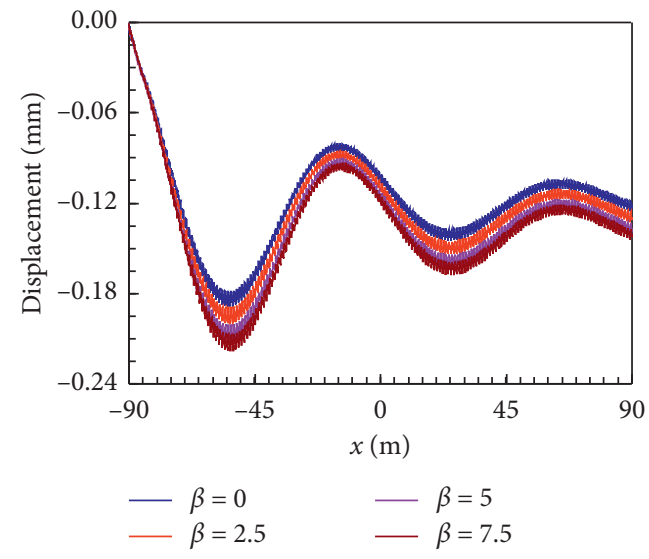

(b)

FIGURE 13: The history of vertical displacements of the wheel axle corresponding with location of the moving vehicle: (a) $v=50 \mathrm{~m} / \mathrm{s}$ and (b) $v=75 \mathrm{~m} / \mathrm{s}$.

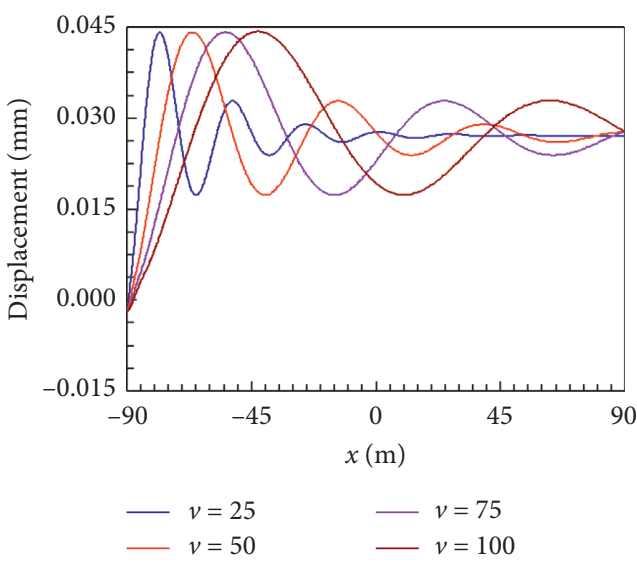

(a)

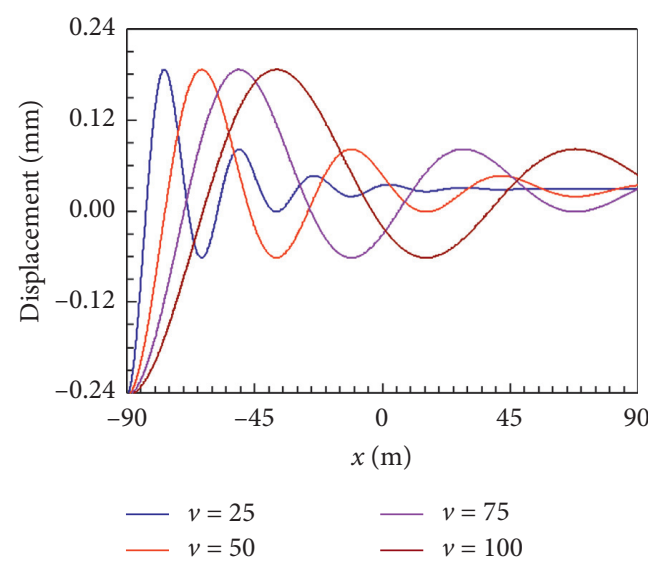

(b)

FIGURE 14: The history of vertical displacements corresponding with location of the moving vehicle: (a) bogie and (b) body. 
contacting a response between vehicle and tracks considering the loss of contact force between the structure and the vehicle.

Finally, the influence of moving velocities on the dynamic response of the vehicle is plotted in Figure 14. It can be also seen that the moving velocity has effects on the history of vertical displacement of the bogie and body with $\beta=0.25$. It does not increase the amplitude of the displacement, but it changed the vibration characteristic of moving the train. Hence, it changed the vibrating period of the train.

It can be seen that consideration of the influence of the foundation mass in the problem of dynamic analysis response of track-train interaction is meaningful and agreed with practical application. The foundation mass caused the increase in general vibration mass, and then it also caused the foundation to become softer. Because the stiffness of the foundation is not varied, the vibration mass of the foundation is increasing with the increase in a characteristic parameter of the influence of the foundation mass. Hence, it decreases the dynamic characteristic of the system which caused the increases in the dynamic response under a moving vehicle.

\section{Conclusions}

The paper presented a procedure of the finite-element method to analyze the dynamic response of track-train interaction on the nonlinear dynamic foundation. In each time step, the general stiffness of the structure is described as a nonlinear function dependent on time displacement at each point of the foundation and the accuracy of the solution based on the above procedure was verified with these results in the literature. At the same time, a characteristic parameter of the influence of the foundation mass on the dynamic response of the track-train interaction is investigated. The investigation results show that the influence of foundation on the dynamic response to the structural system is significant and changed the dynamic characteristic of the structure system. Therefore, the vibration amplitude of the track and the moving vehicle system is almost more increasing than without the effect of the foundation mass in many input cases such as foundation stiffness, viscous damping, and moving velocity. So, the influence of the foundation mass on the dynamic response of the structure must be considered in the problem of analysis response of structure-foundation interaction.

\section{Data Availability}

The data used to support the findings of this study are available from the corresponding author upon request.

\section{Conflicts of Interest}

The authors declare that they have no conflicts of interest.

\section{Acknowledgments}

This research was funded by the Vietnam National Foundation for Science and Technology Development (NAFOSTED), under grant no. 107.01-2017.23.

\section{References}

[1] E. Winkler, Die Lehre von der Elastizitat und Festigkeit, Dominicus, Prague, 1867.

[2] A. A. Al-Azzawi, "Analysis of timoshenko beam resting on nonlinear compressional and frictional winkler foundation," Journal of Engineering and Applied Sciences, vol. 6, no. 11, pp. 100-113, 2011.

[3] U. Bhattiprolu, A. Bajaj, and P. Davies, "Response of a beam on a non-linear tensionless viscoelastic foundation," in Proceedings of the 7th European Nonlinear Dynamics Conference, pp. 24-29, Rome, Italy, 2011.

[4] P. Jorge Castro, F. M. F. Simoes, and A. Pinto Costa, "Dynamics of beams on non-uniform nonlinear foundations subjected to moving load," Computers and Structures, vol. 148, pp. 26-34, 2011.

[5] H. Ding, K.-L. Shi, L.-Q. Chen, and S.-P. Yang, "Dynamic response of an infinite Timoshenko beam on a nonlinear viscoelastic foundation to a moving load," Nonlinear Dynamics, vol. 73, no. 1-2, pp. 285-298, 2013.

[6] D. Froio, R. Moioli, and E. Rizzi, "Numerical dynamic analysis of beams on nonlinear elastic foundations under harmonic moving load," in Proceedings of the VII European Congress on Computational Methods in Applied Sciences and Engineering, pp. 1-16, Crete Island, Greece, 2016.

[7] T. S. Jang, "A new semi-analytical approach to large deflections of Bernoulli-Euler-v. Karman beams on a linear elastic foundation: nonlinear analysis of infinite beams," International Journal of Mechanical Sciences, vol. 66, pp. 22-32, 2013.

[8] A. Kacar, H. Tan, and M. Kaya, "Free vibration analysis of beams on variable Winkler elastic foundation by using the differential transform method," Mathematical and Computational Applications, vol. 16, no. 3, pp. 773-783, 2011.

[9] J. S. Kim and M. K. Kim, “The dynamic response of an EulerBernoulli beam on an elastic foundation by finite element analysis using the exact stiffness matrix," Journal of Physics Conference Series, vol. 382, Article ID 012008, 2012.

[10] A. D. Senalp, A. Arikoglu, I. Ozkol, and V. Z. Dogan, "Dynamic response of a finite length Euler-Bernoulli beam on linear and nonlinear viscoelastic foundations to a concentrated moving force," Journal of Mechanical Science and Technology, vol. 24, no. 10, pp. 1957-1961, 2010.

[11] S. Zhou, G. Song, R. Wang, Z. Ren, and B. Wen, "Nonlinear dynamic analysis for coupled vehicle-bridge vibration system on nonlinear foundation," Mechanical Systems and Signal Processing, vol. 87, pp. 259-278, 2017.

[12] M. M. Filonenko-Borodich, "Some approximate theories of elastic foundation," Uchenyie Zapiski Moskovskogo Gosudarstvennogo Universiteta Mekhanica, vol. 46, pp. 3-18, 1940.

[13] M. Hetényi, Beams on Elastic Foundation: Theory with Applications in the Fields of Civil and Mechanical Engineering, University of Michigan Press, Ann Arbor, MI, USA, 1946.

[14] P. L. Pasternak, On a New Method of Analysis of an Elastic Foundation by Means of Two Constants, Gosudarstvennoe Izdatelstvo Literaturi po Stroitelstvui Arkhitekture, Moscow, Russia, 1954.

[15] E. Reissner, "A note on deflections of plates on a viscoelastic foundation," Journal of Applied Mechanics, vol. 25, pp. 44$155,1964$.

[16] A. D. Kerr, "Elastic and viscoelastic foundation models," Journal of Applied Mechanics, vol. 31, no. 3, pp. 491-498, 1964.

[17] N. Andrea and L. Luca, "On the contact problem of beams resting on tensionless two-parameter foundations," in Proceedings of the XX AMIETA Congress, Bolognia, Italy, 2011. 
[18] M. Attar, A. Karrech, and K. Regenauer-Lieb, "Free vibration analysis of a cracked shear deformable beam on a two-parameter elastic foundation using a lattice spring model," Journal of Sound and Vibration, vol. 333, no. 11, pp. 23592377, 2014.

[19] A. Fallah and M. M. Aghdam, "Nonlinear free vibration and post-buckling analysis of functionally graded beams on nonlinear elastic foundation," European Journal of Mechanics A/Solids, vol. 30, pp. 1-13, 2011.

[20] M. A. Hamarat, Ü. H. Çalık Karaköse, and E. Orakdöğen, "Seismic analysis of structures resting on two parameter elastic foundation," in Proceedings of the 15th World Conference on Earthquake Engineering, Lisbon, Portugal, 2012.

[21] M. T. Hassan and M. Nassar, "Analysis of stressed Timoshenko beams on two parameter foundations," KSCE Journal of Civil Engineering, vol. 19, no. 1, pp. 173-179, 2015.

[22] L. Yang and X. Jiang, "Nonlinear vibration of rectangular orthotropic plates resting on the three-parameter foundations in thermal environments," Electronic Journal of Geotechnical Engineering, vol. 19, pp. 4215-4226, 2014.

[23] Z. Lu, H. Yao, Y. Zhan, and Z. Hu, "Vibrations of a plate on a two-parameter foundation subjected to moving rectangular loads of varying velocities," Journal of Vibroengineering, vol. 16, no. 3, pp. 1543-1554, 2014.

[24] H. Matsunaga, "Vibration and buckling of deep beam-columns on two-parameter elastic foundations," Journal of Sound and Vibration, vol. 228, no. 2, pp. 359-376, 1999.

[25] K. Morfidis, "Vibration of Timoshenko beams on three-parameter elastic foundation," Computers \& Structures, vol. 88, no. 5-6, pp. 294-308, 2010.

[26] V. Patil, V. Sawant, and K. Deb, "Finite element analysis of rigid pavement on a nonlinear two parameter foundation model," International Journal of Geotechnical Engineering, vol. 6, no. 3, pp. 275-286, 2012.

[27] B. S. Ratnam, G. V. Rao, and G. R. Janardhana, "Study of dynamic stability of simply supported beams on Pasternak foundation considering the effect of first transition foundation parameter," ZAMM-Journal of Applied Mathematics and Mechanics, vol. 92, no. 6, pp. 490-496, 2012.

[28] E. J. Sapountzakis and A. E. Kampitsis, "Nonlinear analysis of shear deformable beam-columns partially supported on tensionless three-parameter foundation," Archive of Applied Mechanics, vol. 81, no. 12, pp. 1833-1851, 2011.

[29] R. U. A. Uzzal, R. B. Bhat, and W. Ahmed, "Dynamic response of a beam subjected to moving load and moving mass supported by Pasternak foundation," Shock and Vibration, vol. 19, no. 2, pp. 205-220, 2012.

[30] T. Yokoyama, "Vibration analysis of Timoshenko beamcolumns on two-parameter elastic foundations," Computers \& Structures, vol. 61, no. 6, pp. 995-1007, 1996.

[31] Y. Yu and B. Wu, "Analytical approximate solutions to largeamplitude free vibrations of uniform beams on Pasternak foundation," International Journal of Applied Mechanics, vol. 6, no. 6, Article ID 1450075, 2014.

[32] Y. Zhang, "Tensionless contact of a finite beam resting on Reissner foundation," International Journal of Mechanical Sciences, vol. 50, no. 6, pp. 1035-1041, 2008.

[33] D. Zhou, Y. K. Cheung, S. H. Lo, and F. T. K. Au, “Threedimensional vibration analysis of rectangular thick plates on Pasternak foundation," International Journal for Numerical Methods in Engineering, vol. 59, no. 10, pp. 1313-1334, 2004.

[34] T. P. Nguyen and D. T. Pham, "The influence of mass of twoparameter elastic foundation on dynamic responses of beam subjected to a moving mass," KSCE Journal of Civil Engineering, vol. 20, no. 7, pp. 2842-2848, 2016.

[35] T. P. Nguyen, D. T. Pham, and P. H. Hoang, "A new foundation model for dynamic analysis of beams on nonlinear foundation subjected to a moving mass," Procedia Engineering, vol. 142, pp. 165-172, 2016.

[36] P. T. Nguyen, T. D. Pham, and H. P. Hoang, "A dynamic foundation model for the analysis of plates on foundation to a moving oscillator," Structural Engineering and Mechanics, vol. 59, no. 6, pp. 1019-1035, 2016.

[37] D. T. Pham, P. H. Hoang, and T. P. Nguyen, "Experiments on influence of foundation mass on dynamic characteristic of structures," Structural Engineering and Mechanics, vol. 65, no. 5, pp. 505-511, 2018.

[38] C. G. Koh, J. S. Y. Ong, D. K. H. Chua, and J. Feng, "Moving element method for train-track dynamics," International Journal for Numerical Methods in Engineering, vol. 56, no. 11, pp. 1549-1567, 2003. 